\title{
A Case of Esophageal Squamous Cell Carcinoma in situ Arising from Esophageal Squamous Papilloma
}

\author{
Jae Yeong Cho ${ }^{1}$, Dae Young Cheung ${ }^{1}$, Tae Jung Kim ${ }^{2}$ and Jae Kwang Kim ${ }^{1}$ \\ Department of ${ }^{1}$ Internal Medicine, ${ }^{2}$ Hospital Pathology, The Catholic University of Korea College of Medicine, Seoul, Korea
}

Squamous papilloma is a common benign tumor of the esophagus. Patients with papilloma are usually asymptomatic, and they are diagnosed incidentally during esophagogastroduodenoscopy. Most papillomas are small and easily removed by forceps biopsy. Recurrence of papilloma after removal is rare. Human papilloma virus infection is supposed to play a role in the development of esophageal papilloma; however, malignant transformation of papilloma is extremely unusual. Here, we report a case of malignant transformation of esophageal squamous papilloma at the gastroesophageal junction into squamous cell carcinoma in situ, which was treated by endoscopic submucosal dissection. Clin Endosc 2019;52:72-75

Key Words: Papilloma; Carcinoma, squamous cell; Carcinoma in situ; Endoscopy, digestive system

\section{INTRODUCTION}

Squamous papilloma is a benign tumor of the esophagus. Patients with papilloma are usually asymptomatic and are diagnosed incidentally during esophagogastroduodenoscopy (EGD). A majority of the papillomas present as polyps with a wart-like shape, exophytic growth, and crossing surface vessels under narrow-band imaging. The common locations of papilloma are the mid- and lower esophagus. ${ }^{1}$ We observed an unusual case of malignant transformation of esophageal papilloma into squamous cell carcinoma in situ, which occurred at the gastroesophageal junction (GEJ).

Received: March 21, 2018 Revised: June 14, 2018

Accepted: June 14, 2018

Correspondence: Dae Young Cheung

Department of Internal Medicine, Yeouido St. Mary's Hospital, The Catholic University of Korea College of Medicine, 222 Banpo-daero, Seocho-gu, Seoul 06591, Korea

Tel: +82-2-3779-1519, Fax: +82-2-3779-1331, E-mail: adagio@catholic.ac.kr ORCID: https://orcid.org/0000-0003-4150-3555

(cc) This is an Open Access article distributed under the terms of the Creative Commons Attribution Non-Commercial License (http://creativecommons.org/ licenses/by-nc/3.0) which permits unrestricted non-commercial use, distribution, and reproduction in any medium, provided the original work is properly cited.

\section{CASE REPORT}

A 44-year-old woman visited the outpatient clinic with reports of EGD examination showing a GEJ polyp. EGD had been performed as part of a health promotion screening, and the patient denied having any subjective symptom or past medical history including smoking and alcohol consumption. She looked generally healthy. Physical examination and laboratory test revealed that all values were within the normal reference range.

EGD examination revealed that the polyp was located just on the squamocolumnar junction of the GEJ and presented as a $1.5-\mathrm{cm}$ protruding polypoid mass with an irregular and nodular surface (Fig. 1). Forceps biopsy was performed to exclude malignant tumor. Microscopic examination revealed squamous papilloma showing papillary squamous epithelium with a fibrovascular core. Squamous epithelial cells of the papilloma showed koilocytosis with irregular nuclear membrane and perinuclear halo, which histologically confirmed the presence of human papillomavirus infection (Fig. 2).

After obtaining informed consent from the patient, endoscopic mucosal resection was performed to remove the whole papilloma at the GEJ to avoid a possible increase in the size of the tumor. Histological examination of the resected specimen 
revealed a nodular mass with papillary growth consisting of squamous cell epithelium with a well-structured inner fibrovascular core, which was compatible with squamous papilloma. The specimen showed complete and curative resection, without involvement of the lateral or vertical margin.

Two years later, the patient revisited our clinic for esophageal reflux symptoms. Follow-up EGD incidentally revealed a polyp at the GEJ at the exact spot of the previously removed papilloma. The polyp measured approximately $1.0 \mathrm{~cm}$ and had a morphology similar to that of the previous papilloma (Fig. 3), suggesting recurrence. Although the polyp was smaller than that detected 2 years previously, endoscopic sub-

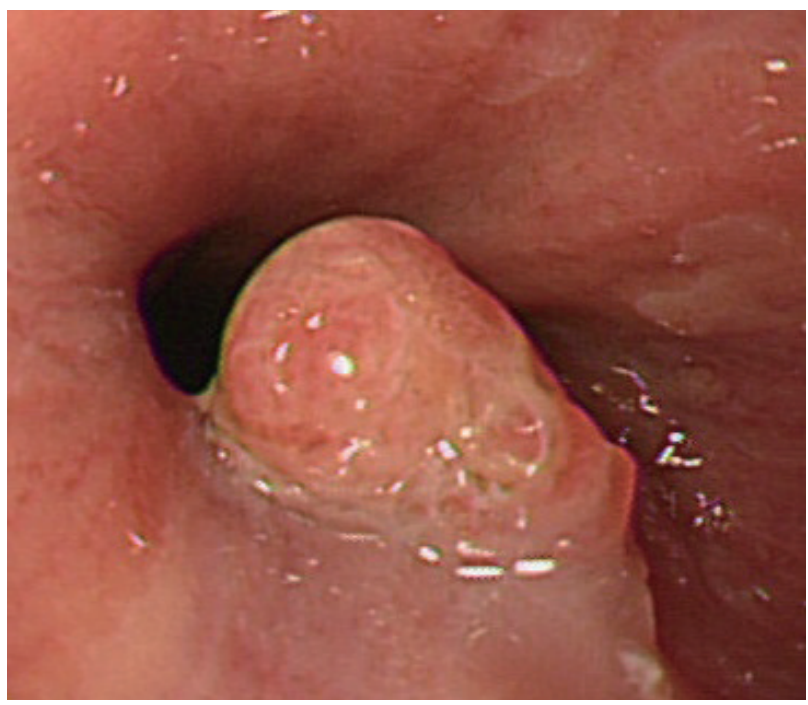

Fig. 1. Endoscopic appearance. A round, protruding polyp measuring $1.0 \mathrm{~cm}$, located at the squamocolumnar junction of the gastroesophageal junction. The polyp had lobulated surface and slight nodularity, and the surface glossiness seemed intact. mucosal dissection was performed owing to fibrotic scarring and non-lifting sign at the anal side of the polyp (Fig. 4). The polyp was removed en bloc and completely, without marginal involvement. Microscopic examination revealed nodular mass with papillary growth. Histologic examination revealed usual papilloma showing papillary squamous epithelium, with a well-developed fibrovascular core. However, multifocal severe squamous atypia was observed throughout the mucosal epithelium, compatible with squamous cell carcinoma in situ (Fig. 5). The patient was finally diagnosed with squamous cell carcinoma in situ arising from esophageal squamous papilloma.

\section{DISCUSSION}

Esophageal squamous papilloma is rarely symptomatic and is usually encountered incidentally during EGD in patients, with the reported incidence varying from $0.01 \%$ to $0.45 \%{ }^{2,3}$ Individuals in their fifties and sixties are commonly affected. ${ }^{1}$ The endoscopic appearance of esophageal squamous papilloma is quite typical, with a wart-like exophytic mass that is usually white in color. ${ }^{4}$ Forceps biopsy enables sufficient removal of the mass and its histological confirmation. Most studies conducted in Western countries showed male dominance or nearly equal sex distribution for esophageal squamous papilloma. However, studies conducted in Asian countries have shown that women are more commonly diagnosed with esophageal papilloma than men are. ${ }^{4}$ With regard to the tumor site, esophageal papilloma is typically located in the mid- to distal esophagus. ${ }^{1,5}$ The exact etiology of the lesion is still unclear. Considering the high prevalence of papilloma at the lower third of the esophagus, chronic irritation is sug-
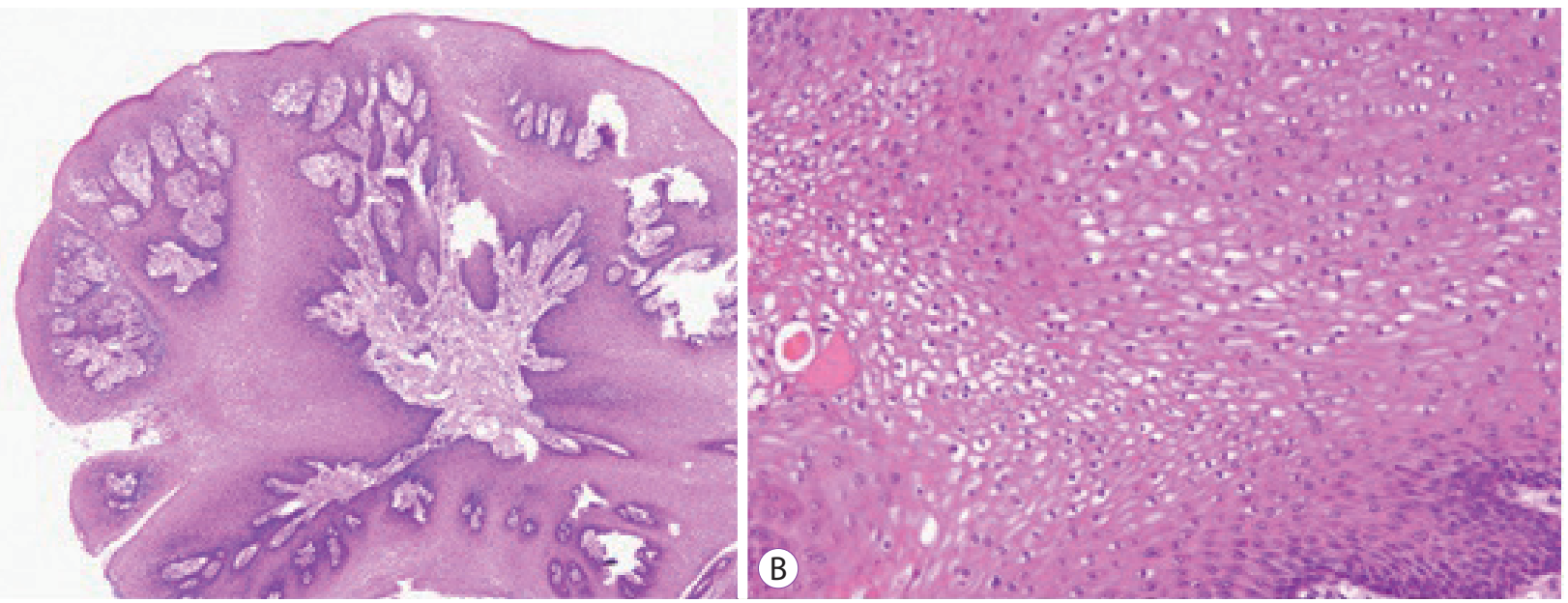

Fig. 2. Histologic findings of the specimen. Microscopic examination revealed squamous papilloma with papillary epithelial proliferation with the fibrovascular core at low-power magnification $(A, H e m a t o x y l i n$ and eosin $[H \& E]$ stain, $\times 40)$. The squamous cell showed koilocytosis with nuclear irregularity and perinuclear halo $(B, H \& E$ stain, $\times 200$ ). 
gested as a causative mechanism along with gastroesophageal reflux disease, chemical injury, and mechanical injury. Infection by human papilloma virus (HPV) is another possible pathogenesis. ${ }^{5} \mathrm{HPV}$-mediated pathogenesis from papilloma to carcinoma is well known in the cervix, anogenital region, and larynx. However, the role of HPV in esophageal carcinogenesis is still debatable. Pantham et al. reported that $47.4 \%$ of papilloma lesions were associated with the high-risk HPV serotype $16 .{ }^{6}$ Bohn et al. reported that $85.7 \%$ of papilloma lesions were associated with low-risk HPV serotypes. ${ }^{7}$ Syrjänen et al. reported that HPV detection in esophageal papilloma does not reach statistical significance because of the different detection methods used and different geographical regions of the patients. ${ }^{8}$ Our experience of esophageal papilloma that

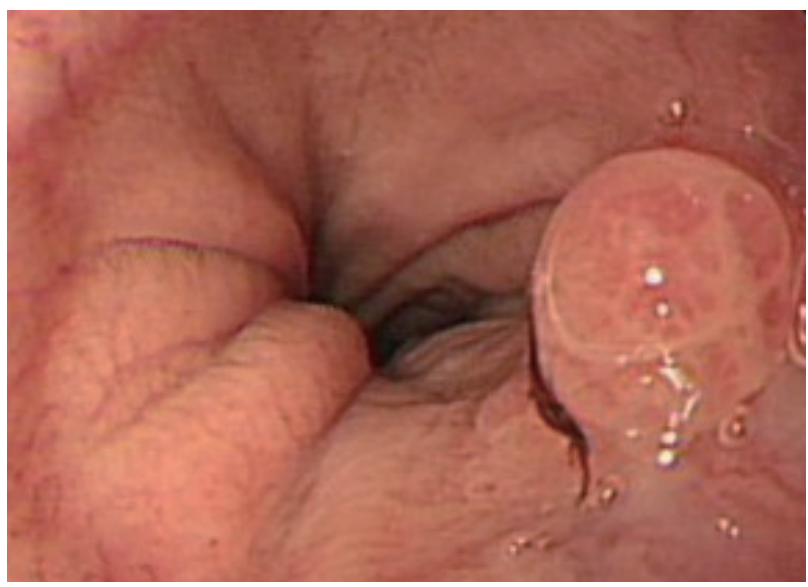

Fig. 3. Endoscopic appearance. A polyp recurred at the squamocolumnar junction of the gastroesophageal junction at the same spot where the papilloma had been removed 2 years previously. The polyp had a smooth surface with shallow lobulation. Gross examination was not suggestive of dysplasia or carcinoma progressed to carcinoma in situ suggests the possibility of HPV infection in the malignant transformation of indolent papilloma. However, immunohistochemical staining for HPV showed negative results in our patient.

Specific treatment for esophageal papilloma is not difficult. Most papillomas are benign and small, and they are easily removed by forceps biopsy. However, ensuring definite removal of papilloma is important when the lesion shows an unusually large size on symptomatic presentation such as bleeding or foreign body sensation, and when an atypical change is detected on histological examination. ${ }^{9}$ Very few studies have reported the carcinomatous transformation of

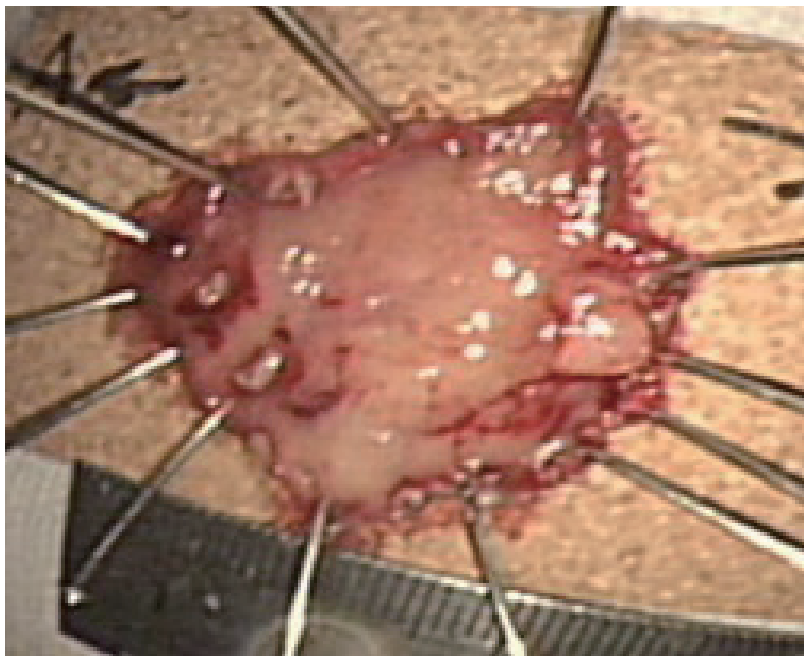

Fig. 4. Gross appearance of the resected specimen by endoscopic submucosal dissection technique. A specimen measuring $3.0 \times 2.8 \mathrm{~cm}$, including a protruding mass at the 3 o'clock position, was resected en bloc. The oral side had a relatively narrow free margin, contrary to the anal side (9 o'clock position). Grossly, the circumferential lateral margin was free from polyp involvement.
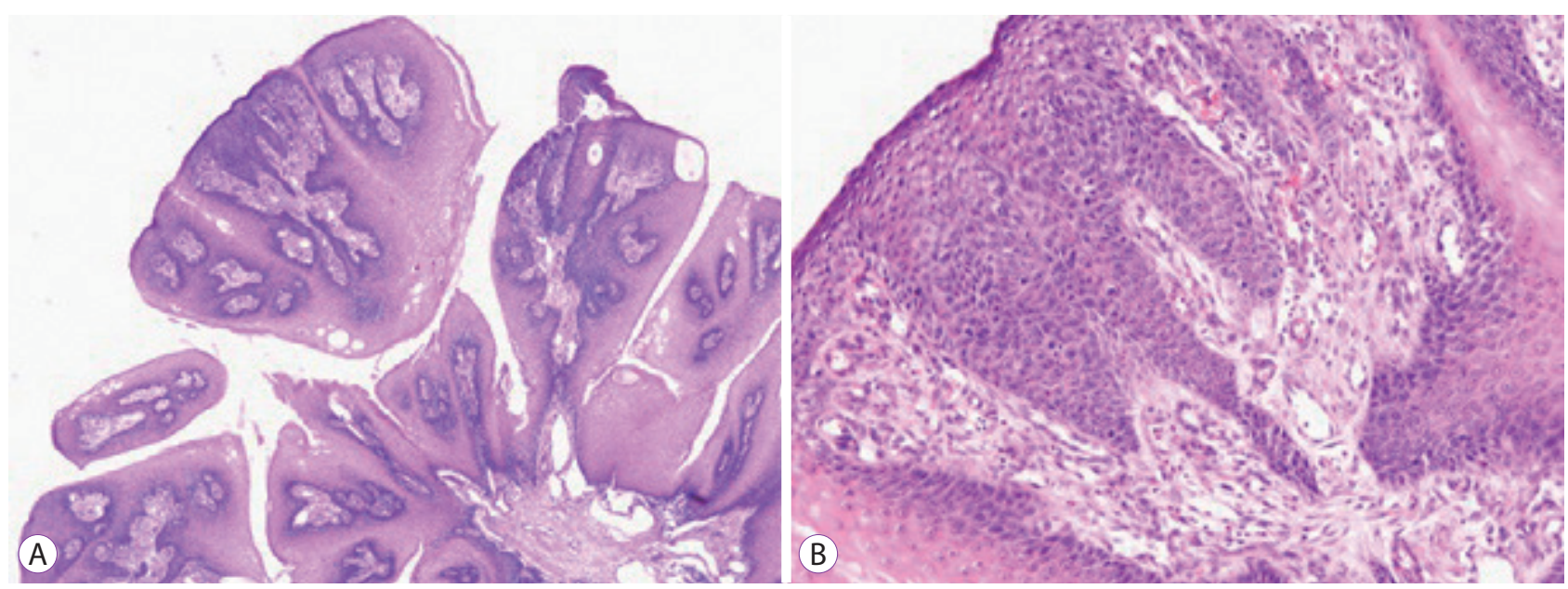

Fig. 5. Histologic findings of the specimen. The polyp showed usual morphological features of squamous papilloma at low-power magnification (A, Hematoxylin and eosin [H\&E] stain, $\times 40$ ) but multifocal severe squamous atypia throughout the mucosal epithelium, which was compatible with squamous carcinoma in situ (B, H\&E stain, $\times 200$ ). 
esophageal papilloma. ${ }^{10}$ In a French cohort, $1(1.3 \%)$ out of 78 cases of esophageal papilloma developed into squamous cell carcinoma at follow-up endoscopy performed after 2 years. ${ }^{3}$ Although various ablative techniques can be employed, ${ }^{11,12}$ endoscopic mucosal resection or endoscopic submucosal dissection is a better choice of treatment for whole tissue acquisition according to the papilloma size and shape. ${ }^{13,14}$ Esophageal papillomatosis is a condition in which numerous papillomas develop in the esophagus. A few reports on cancer arising from papillomatosis exist. Attila et al. described a case of esophageal papillomatosis complicated by the development of esophageal invasive squamous cell carcinoma diagnosed after esophagectomy. ${ }^{15}$ Wolfsen et al. report a case of esophageal papillomatosis associated with squamous cell carcinoma after photodynamic therapy and endoscopic metal stent placement. ${ }^{12}$ However, we reported an unusual case of malignant transformation of a papilloma that developed at the GEJ in a patient without any risk factors.

\section{Conflicts of Interest}

The authors have no financial conflicts of interest.

\section{REFERENCES}

1. Takeshita K, Murata S, Mitsufuji S, et al. Clinicopathological characteristics of esophageal squamous papillomas in Japanese patients--with comparison of findings from Western countries. Acta Histochem Cytochem 2006;39:23-30.

2. Mosca S, Manes G, Monaco R, Bellomo PF, Bottino V, Balzano A. Squamous papilloma of the esophagus: long-term follow up. J Gastroenterol Hepatol 2001;16:857-861.
3. d'Huart MC, Chevaux JB, Bressenot AM, et al. Prevalence of esophageal squamous papilloma (ESP) and associated cancer in northeastern France. Endosc Int Open 2015;3:E101-E106.

4. Wong MW, Bair MJ, Shih SC, et al. Using typical endoscopic features to diagnose esophageal squamous papilloma. World J Gastroenterol 2016;22:2349-2356.

5. Odze R, Antonioli D, Shocket D, Noble-Topham S, Goldman H, Upton M. Esophageal squamous papillomas. A clinicopathologic study of 38 lesions and analysis for human papillomavirus by the polymerase chain reaction. Am J Surg Pathol 1993;17:803-812.

6. Pantham G, Ganesan S, Einstadter D, Jin G, Weinberg A, Fass R. Assessment of the incidence of squamous cell papilloma of the esophagus and the presence of high-risk human papilloma virus. Dis Esophagus 2017;30:1-5.

7. Bohn OL, Navarro L, Saldivar J, Sanchez-Sosa S. Identification of human papillomavirus in esophageal squamous papillomas. World J Gastroenterol 2008;14:7107-7111.

8. Syrjänen K, Syrjänen S. Detection of human papillomavirus in esophageal papillomas: systematic review and meta-analysis. Apmis 2013;121:363-374.

9. Inomata S, Aoyagi K, Eguchi K, Sakisaka S. Giant esophageal papilloma. Gastrointest Endosc 2004;60:430.

10. Reynoso J, Davis RE, Daniels WW, Awad ZT, Gatalica Z, Filipi CJ. Esophageal papillomatosis complicated by squamous cell carcinoma in situ. Dis Esophagus 2004;17:345-347.

11. Del Genio G, Del Genio F, Schettino P, et al. Esophageal papilloma: flexible endoscopic ablation by radiofrequency. World J Gastrointest Endosc 2015;7:290-294.

12. Wolfsen HC, Hemminger LL, Geiger XJ, Krishna M, Woodward TA. Photodynamic therapy and endoscopic metal stent placement for esophageal papillomatosis associated with squamous cell carcinoma. Dis Esophagus 2004;17:187-190.

13. Kim E, Byrne MF, Donnellan F. Endoscopic mucosal resection of esophageal squamous papillomatosis. Can J Gastroenterol 2012;26:780-781.

14. Park JS, Youn YH, Park JJ, Kim JH, Park H. Clinical outcomes of endoscopic submucosal dissection for superficial esophageal squamous neoplasms. Clin Endosc 2016;49:168-175.

15. Attila T, Fu A, Gopinath N, Streutker CJ, Marcon NE. Esophageal papillomatosis complicated by squamous cell carcinoma. Can J Gastroenterol 2009;23:415-419. 